\title{
A Small-scale Procedure for Acid-catalyzed Ketal Formation
}

\author{
Austin C. Wright, Yun Emily Du, and Brian M. Stoltz
}

J. Org. Chem., Just Accepted Manuscript • DOI: 10.1021/acs.joc.9b01541 • Publication Date (Web): 12 Aug 2019

Downloaded from pubs.acs.org on August 12, 2019

\section{Just Accepted}

"Just Accepted" manuscripts have been peer-reviewed and accepted for publication. They are posted online prior to technical editing, formatting for publication and author proofing. The American Chemical Society provides "Just Accepted" as a service to the research community to expedite the dissemination of scientific material as soon as possible after acceptance. "Just Accepted" manuscripts appear in full in PDF format accompanied by an HTML abstract. "Just Accepted" manuscripts have been fully peer reviewed, but should not be considered the official version of record. They are citable by the Digital Object Identifier (DOI®). "Just Accepted" is an optional service offered to authors. Therefore, the "Just Accepted" Web site may not include all articles that will be published in the journal. After a manuscript is technically edited and formatted, it will be removed from the "Just Accepted" Web site and published as an ASAP article. Note that technical editing may introduce minor changes to the manuscript text and/or graphics which could affect content, and all legal disclaimers and ethical guidelines that apply to the journal pertain. ACS cannot be held responsible for errors or consequences arising from the use of information contained in these "Just Accepted" manuscripts. 
For nearly a century, the venerable Dean-Stark apparatus has been a mainstay in organic chemistry as a means to perform acid-catalyzed dehydrative reactions. ${ }^{1}$ However, this technique is not without limitations, specifically owing to its lackluster performance on small scale. This is particularly problematic in the context of exploratory chemistry, which is ideally performed using minimal amounts of substrate. To obviate this issue, enterprising synthetic chemists have discovered a number of experimental workarounds. In particular, the Noyori ketalization protocol is conducive to small-scale chemistry, ${ }^{2}$ but these conditions generally require cryogenic temperatures and have a comparatively narrow substrate scope. Additionally, a procedural textbook by Williamson and Masters outlines an elegant apparatus to effect the microscale dehydrative esterification of acids under Dean-Stark conditions. ${ }^{3}$ However, this procedure requires a relatively elaborate experimental setup and lacks scalability. Our lab has obviated these issues with the following modified and experimentally simple procedure. Herein, we wish to disclose the first formal report of acid-catalyzed dehydrative ketal protections using recyclable molecular sieves.

During our synthetic campaign toward several members of the curcusone family of natural products, ${ }^{4}$ we discovered a simple modified procedure for the traditional Dean-Stark apparatus. In essence, this apparatus replaces a Dean-Stark trap with an addition funnel containing $4 \AA$ molecular sieves that is mounted directly above the reaction flask. It should be noted that the molecular sieves do not come in direct contact with the reaction mixture, as they are known to counterproductively serve as acid scavengers. ${ }^{5}$ Nevertheless, we have since found this procedure to be quite general and user-friendly.

To highlight the advantages of this system, we attempted to replicate a Dean-Stark-mediated procedure for the ketalization of enone 1 (Scheme 1). ${ }^{6}$ We found the yields for this transformation to be somewhat erratic, particularly in the context of scale. We often visually observed water condensation

at the base of the reflux condenser, suggesting that the DeanStark trap was not thoroughly sequestering moisture from the reaction vessel. We hoped to alleviate these issues by reengineering the classical Dean-Stark procedure. Thus, we adapted the two modified setups detailed below in Figures 1 and 2 (vide infra).

\section{Scheme 1. Problematic Ketalization of Enone 1}

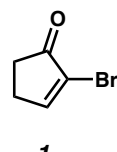

1

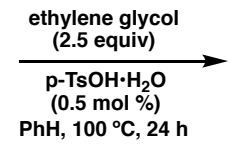

$\mathrm{PhH}, 100^{\circ} \mathrm{C}, 24 \mathrm{~h}$

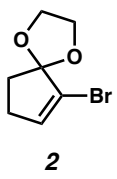

In order to showcase the superior dehydrating ability of this modified system, we performed comparative studies (Table 1). We were pleased to find that this procedure modestly but consistently outperformed the traditional Dean-Stark apparatus on $30-\mathrm{mL}$ scale (Entries 1 and 5, respectively). Encouraged by these results, we next investigated the amenability of the modified procedure toward small-scale chemistry. To our delight, yields proved consistent down to $5-\mathrm{mL}$ scale (Entry 2) and only slightly decreased on 2-mL scale (Entry 3 ), likely due to partial solvent loss. We were further pleased to find that we could achieve similar reactivity on $10 \mathrm{mg}$ of substrate, albeit in more modest yield (Entry 4). As in previous trials, the performance of the Dean-Stark system proved inferior on 5-mL scale (Entry 6) and was simply not verifiable on 2-mL scale due to extensive solvent boil-off (Entry 7). 
Table 1. Comparative Studies on Ketal Formation

\begin{tabular}{|c|c|c|c|c|}
\hline \multirow[b]{4}{*}{ entry } & \multicolumn{3}{|c|}{$\begin{array}{l}\text { ethylene glycol } \\
(2.5 \text { equiv) }\end{array}$} & \multirow[b]{4}{*}{ resulta } \\
\hline & \multirow{3}{*}{$\begin{array}{c}1 \\
\text { scale }\end{array}$} & \multirow{2}{*}{\multicolumn{2}{|c|}{$\begin{array}{c}p-\mathrm{TsOH} \cdot \mathrm{H}_{2} \mathrm{O} \\
(0.5 \mathrm{~mol} \%) \\
\mathrm{PhH}, 100^{\circ} \mathrm{C}, 24 \mathrm{~h}\end{array}$}} & \\
\hline & & & & \\
\hline & & solvent volume & procedure & \\
\hline 1 & $6.00 \mathrm{mmol}$ & $30 \mathrm{~mL}$ & 4Å Mol. Sieves & $67 \%$ NMR yield $b$ \\
\hline 2 & $1.00 \mathrm{mmol}$ & $5 \mathrm{~mL}$ & 4Å Mol. Sieves & $67 \%$ NMR yield \\
\hline 3 & $0.40 \mathrm{mmol}$ & $2 \mathrm{~mL}$ & 4Å Mol. Sieves & $60 \%$ NMR yield \\
\hline 4 & $0.06 \mathrm{mmol}$ & $2 \mathrm{~mL}$ & 4Å Mol. Sieves & $40 \%$ NMR yield $c$ \\
\hline 5 & $6.00 \mathrm{mmol}$ & $30 \mathrm{~mL}$ & Dean-Stark & $61 \%$ NMR yield $b$ \\
\hline 6 & $1.00 \mathrm{mmol}$ & $5 \mathrm{~mL}$ & Dean-Stark & $55 \%$ NMR yield \\
\hline 7 & $0.40 \mathrm{mmol}$ & $2 \mathrm{~mL}$ & Dean-Stark & not determined \\
\hline
\end{tabular}

${ }^{a}$ Conversion was complete after $24 \mathrm{~h} .{ }^{b}$ Average yield of two trials. ${ }^{c} 17$ equivalents of ethylene glycol and $3.3 \mathrm{~mol} \%$ of $p$ $\mathrm{TsOH} \cdot \mathrm{H}_{2} \mathrm{O}$ were used in order to preserve reagent and catalyst concentrations.

Below is our optimized apparatus for non-small-scale reactions (i.e. those containing more than $50 \mathrm{~mL}$ of solvent, Figure 1). The reaction vessel is attached to a pressureequalized addition funnel, the base of which is plugged with cotton and is partially filled with oven-dried, $4 \AA$ molecular sieves (approximately $1 \mathrm{~g}$ for every $10 \mathrm{~mL}$ of solvent). In order to minimize solvent loss, it is best to thoroughly dampen the molecular sieves with the reaction solvent prior to heating. Fixed to the top of the funnel is a reflux condenser. The condenser is capped with a needle-punctured septum (not shown) in order to prevent buildup of pressure under $\mathrm{N}_{2}$. As with standard Dean-Stark technique, it is best to insulate the reaction vessel and addition funnel side arm with cotton and aluminum foil so as to maximize reflux efficiency. We also recommend using a stopcock valve with a large bore diameter (4$6 \mathrm{~mm}$ ), because this can demonstrably improve solvent vapor flux through the drying chamber.

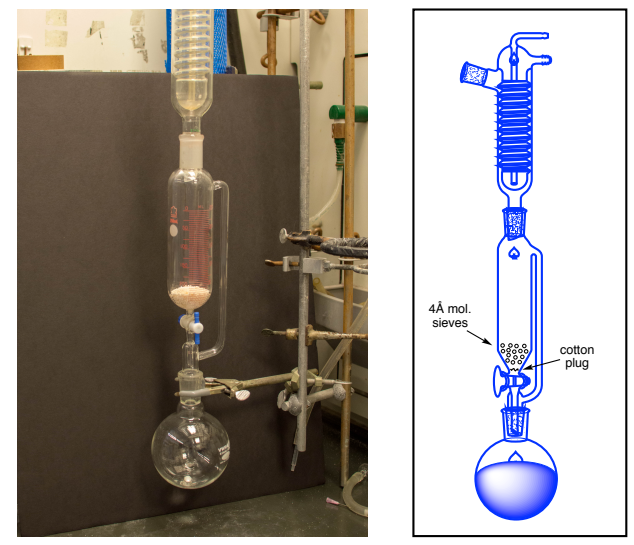

Figure 1. Modified apparatus for large-scale ketalizations.

A very similar apparatus for small-scale reactions is shown below in Figure 2. A larger ratio of molecular sieves is now used to expedite the drying process $(1 \mathrm{~g} / 2 \mathrm{~mL}$ solvent). Due to the smaller surface area of this glass apparatus, the flask and side arm now should only be wrapped with aluminum foil, as additional insulation with glass wool or cotton can lead to solvent boil-off. Using this modification, we have successfully performed ketalizations on as little as $10 \mathrm{mg}$ of material.

To showcase the potentially broad applicability of this dehydrating system, we attempted a ketalization of estrone (3).
Pleasingly, we found that desired ketal $\mathbf{4}$ could be obtained in decent yield under slightly modified reaction conditions (Scheme 2).

Scheme 2. Ketalization of Estrone (3)
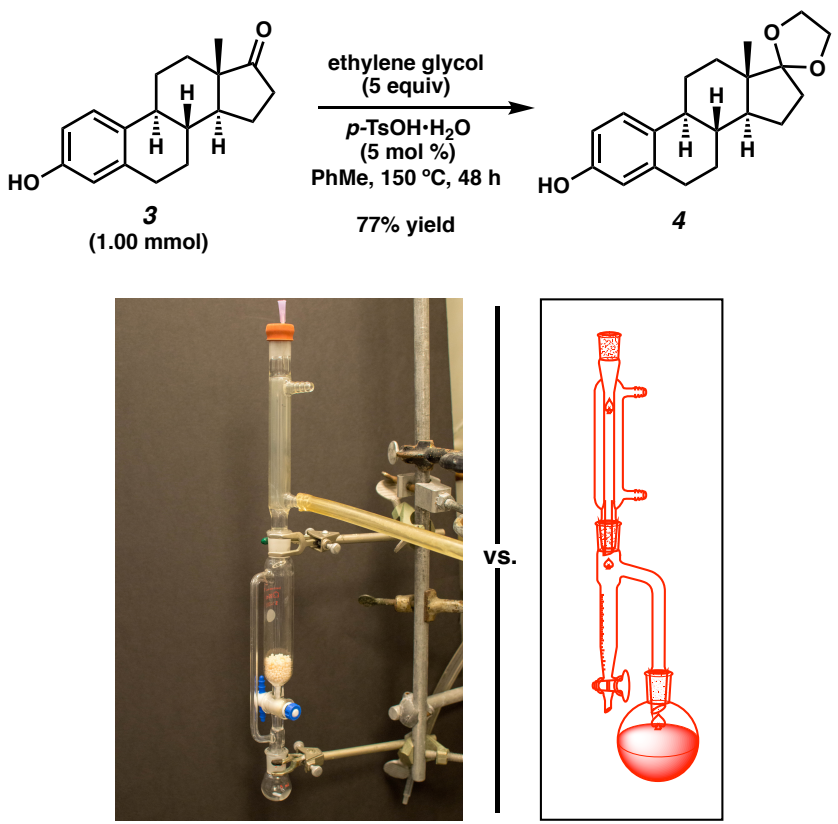

Figure 2. Left: Modified apparatus for small-scale ketalizations; Right: A traditional Dean-Stark apparatus fails on very small scale.

In summary, we have disclosed a modified approach to the traditional Dean-Stark apparatus. In our experience, this procedure consistently demonstrates comparable or superior yields to its experimental predecessor, and it appears to be uniquely amenable to small-scale chemistry. As such, it is our hope that this adapted procedure will become a common alternative experimental technique. We are eager to see what future applications this apparatus will offer to organic synthesis.

\section{Experimental Section}

\section{General Information}

All reactions were performed with non-oven-dried glassware. Commercially available reagents and solvent were used without further purification. Benchtop benzene, ethylene glycol, $p$-toluenesulfonic acid monohydrate, and $4 \AA$ molecular sieve beads were all purchased from Sigma-Aldrich. Recycled molecular sieves were pre-activated by heating in a $130{ }^{\circ} \mathrm{C}$ oven overnight. 2-Bromocyclopent-2-en-1-one (1) was prepared according to known methods. ${ }^{7}$ The external heat of each reaction was modulated to the specified temperatures using an IKAmag temperature controller. Reaction progress was monitored by thin-layer chromatography (TLC), which was performed using E. Merck silica gel 60 F254 precoated glass plates $(0.25 \mathrm{~mm})$ and visualized by UV fluorescence quenching or potassium permanganate. NMR yields were determined by the introduction of an internal standard (1,3,5trimethoxybenzene) upon reaction completion.

\section{General Procedure A (Gram-scale Ketalizations):}

To a solution of substrate in $\mathrm{PhH}(0.2 \mathrm{M})$ were sequentially added ethylene glycol ( 2.5 equiv) and $p-\mathrm{TsOH} \bullet \mathrm{H}_{2} \mathrm{O}(0.5$ mol \%) under air. Meanwhile, an oil bath was preheated to 80 ${ }^{\circ} \mathrm{C}$. An appropriately sized addition funnel was plugged with cotton such that the stopcock valve remained open and unob- 
structed. Oven-dried molecular sieves $(1 \mathrm{~g} / 10 \mathrm{~mL}$ solvent $)$ were added to the funnel, and the sieves were saturated with $\mathrm{PhH}$. The addition funnel was attached to the reaction vessel, and a reflux condenser was fastened to the top of the addition funnel. The entire apparatus was quickly purged with $\mathrm{N}_{2}(\mathrm{x} 3)$. The manifold line was detached from the vessel, and a largegauge needle was inserted into the septum. The reaction flask was submerged in an $80{ }^{\circ} \mathrm{C}$ oil bath, at which point the temperature was increased to $100{ }^{\circ} \mathrm{C}$. Meanwhile, an active "house vacuum" line was attached to the inlet of the reflux condenser. Upon reaching the desired temperature, the reaction flask and addition funnel side arm were thoroughly wrapped with glass wool and aluminum foil, and the reaction was stirred vigorously for $24 \mathrm{~h}$. The apparatus was allowed to cool to room temperature, after which the reaction mixture was passed through a plug of silica (washing with $\mathrm{Et}_{2} \mathrm{O}$ ), concentrated, and purified by column chromatography.

\section{General Procedure B (Milligram-scale Ketalizations):}

To a solution of substrate in $\mathrm{PhH}(0.2 \mathrm{M})$ were sequentially added ethylene glycol (2.5 equiv) and $p-\mathrm{TsOH} \bullet \mathrm{H}_{2} \mathrm{O}(0.5$ mol \%) under air. Meanwhile, an oil bath was preheated to 80 ${ }^{\circ} \mathrm{C}$. An appropriately sized addition funnel was plugged with cotton such that the stopcock valve remained open and unobstructed. Oven-dried molecular sieves $(1 \mathrm{~g} / 2 \mathrm{~mL}$ solvent) were added to the open funnel, and the sieves were saturated with $\mathrm{PhH}$. The addition funnel was attached to the reaction flask, and a reflux condenser was fastened to the top of the addition funnel. The entire apparatus was quickly purged with $\mathrm{N}_{2}(\mathrm{x} 3)$. The manifold line was detached from the vessel, and a largegauge needle was inserted into the septum. The reaction flask was submerged in an $80{ }^{\circ} \mathrm{C}$ oil bath, at which point the temperature was increased to $100{ }^{\circ} \mathrm{C}$. Meanwhile, an active "house vacuum" line was attached to the inlet of the reflux condenser. Upon reaching the desired temperature, the reaction flask and addition funnel side arm were wrapped with a single layer of aluminum foil, and the reaction was stirred vigorously for $24 \mathrm{~h}$. The apparatus was allowed to cool to room temperature, after which the reaction mixture was passed through a plug of silica (washing with $\mathrm{Et}_{2} \mathrm{O}$ ), concentrated, and purified by column chromatography.

\section{Analytical Data for Gram-scale Ketalizations:}

6-bromo-1,4-dioxaspiro[4.4]non-6-ene (2). Prepared according to General Procedure A. Yield $=789.0 \mathrm{mg}(64 \%$, based on $6.00 \mathrm{mmol}$ of enone 1), pale yellow oil. $\mathrm{R}_{f}=0.4$ (20\% EtOAc in hexanes). All analytical data match those previously reported. ${ }^{6}{ }^{1} \mathrm{H} \mathrm{NMR}\left(500 \mathrm{MHz}, \mathrm{CDCl}_{3}\right): \delta 4.83-4.81(\mathrm{t}$, $J=2.7 \mathrm{~Hz}, 1 \mathrm{H}), 4.22-4.16(\mathrm{~m}, 2 \mathrm{H}), 4.02-3.96(\mathrm{~m}, 2 \mathrm{H}), 2.39$ $2.36(\mathrm{~m}, 2 \mathrm{H}), 2.19-2.16(\mathrm{~m}, 2 \mathrm{H})$.

\section{Analytical Data for Milligram-scale Ketalizations:}

6-bromo-1,4-dioxaspiro[4.4]non-6-ene (2). Prepared according to General Procedure B. Yield $=128.5 \mathrm{mg}(63 \%$, based on $1.00 \mathrm{mmol}$ of enone 1), pale yellow oil. $\mathrm{R}_{f}=0.4$ (20\% EtOAc in hexanes). All analytical data match those previously reported. ${ }^{6}{ }^{1} \mathrm{H} \mathrm{NMR}\left(500 \mathrm{MHz}, \mathrm{CDCl}_{3}\right): \delta 4.83-4.81$ (t, $J=2.7 \mathrm{~Hz}, 1 \mathrm{H}), 4.22-4.16(\mathrm{~m}, 2 \mathrm{H}), 4.02-3.96(\mathrm{~m}, 2 \mathrm{H}), 2.39-$ $2.36(\mathrm{~m}, 2 \mathrm{H}), 2.19-2.16(\mathrm{~m}, 2 \mathrm{H})$.

(4aS,4bR,10bS,12aS)-12a-methyl-3,4,4a,4b,5,6,10b,11,12, 12a-decahydro-2H-spiro[chrysene-1,2'-[1,3]dioxolan]-8-ol (4). Adapted from General Procedure B: To a $10 \mathrm{~mL}$ flask equipped with a stir bar were sequentially added estrone (3, $270.4 \mathrm{mg}, 1.00 \mathrm{mmol})$, PhMe $(5 \mathrm{~mL}, 0.2 \mathrm{M}), p-\mathrm{TsOH} \cdot \mathrm{H}_{2} \mathrm{O}$ ( $8.6 \mathrm{mg}, 5.0 \mathrm{~mol} \%$ ), and ethylene glycol ( $280 \mu \mathrm{L}, 5$ equiv). Meanwhile, an oil bath was preheated to $110^{\circ} \mathrm{C}$. An appropri- ately sized addition funnel was plugged with cotton such that the stopcock valve remained open and unobstructed. Ovendried molecular sieves $(2.5 \mathrm{~g})$ were added to the open funnel, and the sieves were saturated with PhMe. The addition funnel was attached to the reaction flask, and a reflux condenser was fastened to the top of the addition funnel. The entire apparatus was quickly purged with $\mathrm{N}_{2}(\mathrm{x} 3)$. The manifold line was detached from the vessel, and a large-gauge needle was inserted into the septum. The reaction flask was submerged in a $110^{\circ} \mathrm{C}$ oil bath, at which point the temperature was increased to 150 ${ }^{\circ} \mathrm{C}$. Meanwhile, an active "house vacuum" line was attached to the inlet of the reflux condenser. Upon reaching the desired temperature, the reaction flask and addition funnel side arm were thoroughly wrapped with glass wool and aluminum foil, and the reaction was stirred vigorously for $48 \mathrm{~h}$. The apparatus was allowed to cool to room temperature, after which the reaction mixture was passed through a plug of silica (washing with $\mathrm{Et}_{2} \mathrm{O}$ ), concentrated, and purified by column chromatography ( $40 \%$ EtOAc in hexanes) to provide ketal $\mathbf{4}$ as a white solid ( $242.3 \mathrm{mg}, 77 \%$ yield). $\mathrm{R}_{f}=0.3$ (35\% EtOAc in hexanes). All analytical data match those previously reported. ${ }^{8}{ }^{1} \mathrm{H}$ NMR $\left(500 \mathrm{MHz}, \mathrm{CDCl}_{3}\right): \delta 7.15(\mathrm{~d}, J=8.4 \mathrm{~Hz}, 1 \mathrm{H}), 6.64(\mathrm{dd}, J=$ $8.4,2.6 \mathrm{~Hz}, 1 \mathrm{H}), 6.58(\mathrm{~d}, J=2.6 \mathrm{~Hz}, 1 \mathrm{H}), 5.39$ (s, $1 \mathrm{H}), 4.02-$ $3.92(\mathrm{~m}, 4 \mathrm{H}), 2.81-2.79(\mathrm{~m}, 2 \mathrm{H}), 2.31$ (ddd, $J=11.4,6.8,3.9$ $\mathrm{Hz}, 1 \mathrm{H}), 2.20(\mathrm{~m}, 1 \mathrm{H}), 2.07$ (ddd, $J=14.3,11.7,2.9 \mathrm{~Hz}, 1 \mathrm{H}$ ), $1.91-1.85(\mathrm{~m}, 2 \mathrm{H}), 1.80-1.78(\mathrm{~m}, 2 \mathrm{H}), 1.58-1.28(\mathrm{~m}, 6 \mathrm{H})$, $0.91(\mathrm{~s}, 3 \mathrm{H})$.

\section{ASSOCIATED CONTENT}

\section{Supporting Information}

The Supporting Information is available free of charge on the ACS Publications website.

${ }^{1} H$ NMR spectra for all known compounds

\section{AUTHOR INFORMATION}

\section{Corresponding Author}

*E-mail: stoltz@caltech.edu

\section{ACKNOWLEDGMENTS}

Caltech and the NSF (1800511) are thanked for funding. We are grateful to Dr. Alexander Sun (Caltech) for photographic assistance.

\section{REFERENCES}

(1) Dean, E. W.; Stark, D. D. A Convenient Method for the Determination of Water in Petroleum and Other Organic Emulsions. J. Ind. Eng. Chem. 1920, 12 (5), 486-490.

(2) Noyori, R.; Murata, S.; Suzuki, M. Trimethylsilyl Triflate in Organic Synthesis. Tetrahedron 1981, 37 (23), 3899-3910.

(3) K. L. Williamson and K. M. Masters, $6^{\text {th }}$ Ed. Macroscale and Microscale Organic Experiments. Cengage Learning: Belmont, CA, 2011, pg. 519.

(4) Naengchomnong, W.; Thebtaranonth, P.; Wiriyachitra, P.; Okamoto, K. T.; Clardy, J. Isolation and Structure Determination of Four Novel Diterpenes from Jatropha Curcus. Tetrahedron Lett. 1986, 27 (22), 2439-2442.

(5) Banks, A. R.; Fibiger, R. F.; Jones, T. A Convenient Synthesis of Methacrylates. J. Org. Chem. 1977, 42 (24), 3965-3966.

(6) Smith, A. B., III; Branca, S. J.; Pilla, N. N.; Guaciaro, M. A. Stereocontrolled Total Synthesis of $( \pm)$-Pentenomycins I-III, Their 
Epimers, and Dehydropentenomycin I. J. Org. Chem. 1982, 47 (10), $1855-1869$.

(7) Hanessian, S.; Mainetti, E.; Lecomte, F. Synthesis and Stereochemical Confirmation of the Secoiridoid Glucosides Nudiflosides D and A. Org. Lett. 2006, 8 (18), 4047-4049.

(8) Vinogradova, E. V.; Park, N. H.; Fors, B. P.; Buchwald, S. L. Palladium-Catalyzed Synthesis of $\mathrm{N}$-Aryl Carbamates. Org. Lett. 2013, 15, 1394-1397. 